\title{
Applying Thermophysics for Wind Turbine Drivetrain Fault Diagnosis using SCADA Data
}

\author{
Yingning Qiu ${ }^{1, *}$, Yanhui Feng ${ }^{1}$, Juan Sun ${ }^{1}$, Wenxiu Zhang ${ }^{1}$, David Infield ${ }^{2}$ \\ ${ }^{1}$ School of Energy and Power Engineering, Nanjing University of Science and Technology, \\ No.200, Xiao Ling Wei, Nanjing, 210094, P.R.China \\ ${ }^{2}$ Department of Electronic and Electrical Engineering, University of Strathclyde, Royal \\ College Building, 204 George Street, Glasgow, G1 1XW, Scotland, United Kingdom.
}

*yingning.qiu@njust.edu.cn

\begin{abstract}
Cost-effective wind turbine diagnosis using SCADA data is a promising technology for future intelligent wind farm operation and management. This paper presents a thermophysics based method for wind turbine drivetrain fault diagnosis. A synthesized thermal model is formed by incorporating thermal mechanisms of the drivetrain into a wind turbine system model. Applications of the model are demonstrated in case studies of the gearbox and generator comparing simulation results and SCADA data analysis. The results show nonlinearity of the gearbox oil temperature rise with wind speed/output power that can effectively indicate gearbox efficiency degradation, which may be attributed to gear transmission problems such as gear teeth wear. Electrical generator faults, such as ventilation failure and winding voltage unbalance will cause changes to heat transfer and result in temperature changes that can be used for diagnosis purposes. This is shown by different patterns of stator winding temperature associated with power generation, while the simulation reveals the thermal mechanism. The method can be applied to diagnose some failure modes which are hard to identify from vibration analysis. The developed thermal model can play a central role for the purpose of fault diagnosis, by deriving relationships between various SCADA signals and revealing changes in the thermophysics of wind turbine operation.
\end{abstract}

\section{Introduction}

With the increasing size of wind turbines (WTs) and wind farm sites increasingly moving from onshore to offshore, wind turbine condition monitoring (CM) and fault diagnosis technology is attracting attention for its potential to reduce maintenance costs and improve WT availability [1,2]. The European project CONMOW assessed the role of a condition monitoring system (CMS) for early fault identification so as to realize condition based maintenance for offshore wind farms [3]. Practical challenges and issues of the cost-effectiveness of CMS were summarized by studying a full list of available commercial CM systems [4]. Different maintenance strategies, CM technology and methodologies for WT operations have been reviewed [5]. A key challenge lies in the integration of low frequency SCADA data and high frequency CMS data towards a comprehensive turbine health monitoring system, [6] and [7]. Conventional CM systems are based on high frequency vibration signal analysis for mechatronic system failure diagnosis. Although monitoring vibration signals is effective for detecting failure modes that have high frequency signal features, it may not be effective for low speed components, for example, the low 
speed shaft of a WT gearbox, which has low frequency signal content (the rotational speed of the WT gearbox input shaft is slow at generally less than $20 \mathrm{rpm}$ for larger turbines). In addition, due to the variable-speed nature of modern wind turbine operation, there is challenge to using conventional spectral based methods for fault diagnosis. These features lead to very low and unstable characteristic frequencies of the rotating components, which can be easily affected by frequency components within the background noise.

Recent research focuses on using SCADA data for automatic fault diagnosis to devise cost-effective condition monitoring solutions, particular for those turbines that do not have an installed CMS, [8] and [9]. Adaptive Neuro-Fuzzy Interference Systems have been proposed and tested for multiple failure modes, [10] and [11]. A Nonlinear State Estimation Technique, [12], has been used for rotor vibration signal analysis and a linear regression model, [13], has been used for generator temperature modelling to track signal deviation for fault detection. Statistical methods, for example Bayesian analysis, are also used to analyse SCADA alarms to identify different failures, for example [14]. Various fault detection approaches are compared for different sub-assemblies of a WT, which can be categorized into three main types: signal trending, artificial intelligence and physical models [15]. For a SCADA-based condition monitoring of WT, comparisons of the three methods has found that the physical model based approach was the most effective, detecting 24 out of 36 major component failures [15]. However, it requires considerable effort to establish the initial model and to identify model parameters. Effectiveness and accuracy of the fault detection algorithms for failure diagnosis are crucial. Although signal trending or artificial intelligence do not require a comprehensive system model they have a potential weakness in relation to fault explanation and identification, especially for unfamiliar faults. WT fault prognosis is a next level required, but also most challenging, in the development of advanced health monitoring, [16] and [17]. It depends strongly on understanding the root cause of WT failures. In this context the physics of WT failure approach is seen as important.

A theoretical cumulative damage model which correlates damage rate to the external environment as well as applied loads is developed to investigate the physics of failure of a WT gearbox [18]. Basic laws of physics are applied to the gearbox to develop an effective fault detection algorithm based on SCADA signals [7]. Although approaches used to study physics of WT failure and system response under failure circumstances are rare they provide an opportunity for fault diagnosis and CM. Research progress has been made on systematic building of a model to reflect the wind turbine's response to gearbox efficiency degradation, [19]. However, its effectiveness for fault diagnosis and WT powertrain condition monitoring have not yet been validated since transmission efficiency is not a directly measurable signal. It is the 
purpose of this paper to present a thermophysics based system simulation to investigate WT powertrain fault features, which is then validated by comparing the model to measureable quantities extracted from SCADA data. Through a detailed analysis of WT system operational principles and fault features, different failure modes can be better understood. Furthermore, external environmental factors that may influence fault symptoms can be identified and excluded.

Firstly, the operational principles and control strategy that apply to a WT powertrain are briefly presented since these form the basis of the physical system model. A thermal model of a WT powertrain is then developed based on the thermophysics of the powertrain components including the gearbox, the lubrication system, and the electrical generator together with its ventilation and cooling system. Based on SCADA data acquired from a wind turbine with known drive train faults, features characterising different failure modes in the gearbox and generator are examined in some detail.

\section{Wind Turbine System Model}

A wind turbine configured with gearbox and Doubly-Fed Induction Generator (DFIG) is illustrated in Fig. 1. Its main components are blades, rotor, pitch control system, gearbox, generator, converter, control system, yaw system, supporting tower etc. All these subsystems are controlled appropriately to facilitate reliable and efficient conversion of energy from the wind. Auxiliary functions within the wind turbine include the cooling, lubrication and protection systems.

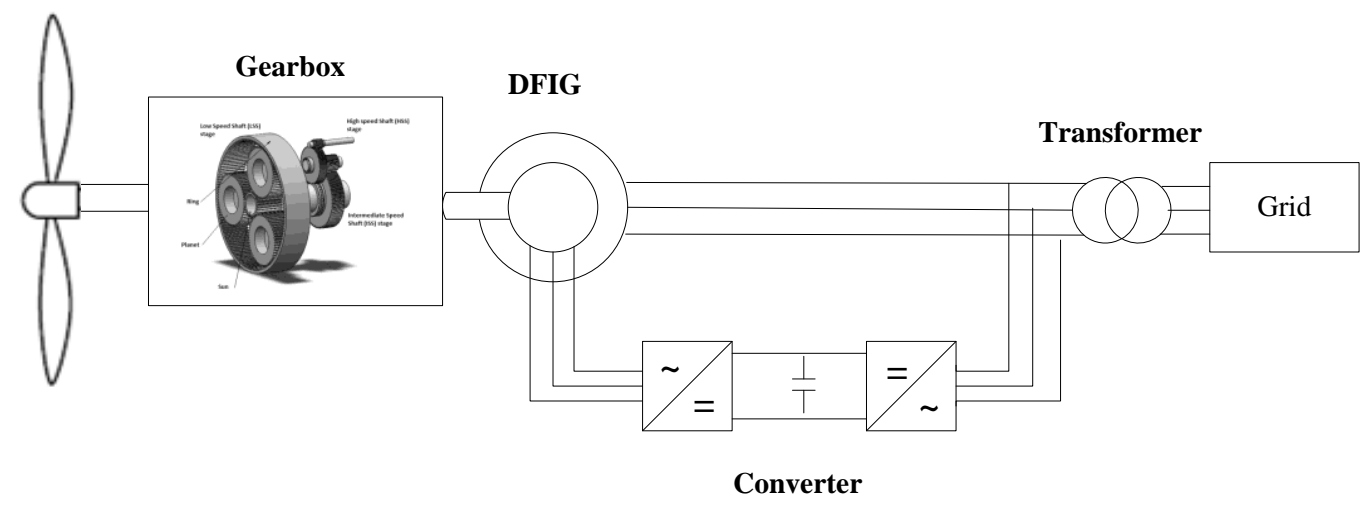

Fig. 1. Schematic illustration of a WT configuration with gearbox and DFIG.

Kinetic energy from the wind is extracted by the wind turbine rotor and transmitted via the gearbox to generator where it is converted into electricity [20-22]. The main sub-systems being considered in this WT model include the rotor aerodynamics, a simplified rigid powertrain model, a DFIG model and control strategy.

The steady state rotor aerodynamics can be represented, [20] and [23], as follows: 


$$
\begin{aligned}
& P=(1 / 2) C_{p}(\lambda, \beta) \rho \pi R^{2} v^{3} \\
& \lambda=\omega_{r} R / v \\
& T_{r}=P_{r} / \omega_{r}=1 / 2 C_{p}(\lambda, \beta) \rho \pi R^{2} v^{3} / \omega_{r} \\
& C_{p}(\lambda, \beta)=(0.44-0.0167 \beta) \cdot \sin [\pi(\lambda-5) /(15-0.3 \beta)] \\
& -0.00184(\lambda-3) \beta
\end{aligned}
$$

where $\mathrm{C}_{\mathrm{p}}$ is the aerodynamic efficiency of the rotor and is a function of tip speed ratio $\lambda$ as defined in (2) and the pitch angle. Rotor torque is determined by mechanical power of rotor and its rotational speed. For equations (1) to (3), $\rho$ is the air density $(\mathrm{kg} / \mathrm{m} 3), \mathrm{P}$ is the power input to the WT $(\mathrm{W})$, $\mathrm{R}$ is rotor radius $(\mathrm{m}), \mathrm{v}$ is wind speed $(\mathrm{m} / \mathrm{s}), \omega_{\mathrm{r}}$ is rotor speed $(\mathrm{rad} / \mathrm{s})$, and $\mathrm{T}_{\mathrm{r}}$ is input WT torque $(\mathrm{N} . \mathrm{m})$.

Simplified rigid drivetrain dynamics are represented by equation (5):

$$
\left(J_{r}+J_{s} n^{2} / \eta\right) d \omega_{r} / d t=T_{r}\left(\omega_{r}, v\right)-(n / \eta) T_{s}\left(\omega_{s}, c\right)
$$

Although simplified, the drivetrain model adopted allows degraded gearbox transmission efficiency to be taken into account. $J_{\mathrm{r}}$ is rotational inertia of the wind turbine rotor $\left(\mathrm{kg} \cdot \mathrm{m}^{2}\right), \mathrm{J}_{\mathrm{g}}$ is rotational inertia of the generator, $\left(\mathrm{kg} \cdot \mathrm{m}^{2}\right), \mathrm{T}_{\mathrm{r}}$ is aerodynamic torque of the wind turbine $(\mathrm{N} \cdot \mathrm{m}) ; \mathrm{T}_{\mathrm{g}}$ is mechanical torque of the high-speed shaft $(\mathrm{N} \cdot \mathrm{m}), \omega_{\mathrm{r}}$ is the rotor speed $(\mathrm{rad} / \mathrm{s}), \omega_{\mathrm{g}}$ is the generator speed $(\mathrm{rad} / \mathrm{s}), \mathrm{n}$ is the gear ratio and $\eta$ is the efficiency of the gearbox. Apart from gear ratio, type of gear and the viscosity of the lubricating oil, the efficiency of a gear transmission also depends on the power transmitted. For a planetary gear, approximately $50 \%$ of the power loss can be assumed to be constant whereas $50 \%$ varies linearly with the transmitted power. Therefore, the energy transmission efficiency of a gearbox is a function of the energy being transferred, [20], and thus depends on the wind speed through equations (1) to (4). Since efficiency generally rises with an increase in transferred energy, WT gearbox efficiency is expected to rise with wind speed. A failing gearbox inevitably causes degradation of power transmission efficiency due to an increase of friction losses, churning losses or rolling losses. The increased energy loss will be ultimately dissipated as heat. This heat will flow from the lubrication oil through the gearbox housing via a mixture conduction, forced and natural convection, and radiation, assisted by the cooling system.

To simulate the dynamics of a DFIG, an equivalent circuit model, as shown in Fig. 2, is established. The transient and steady state performance of the DFIG is described by a set of voltage and flux vector equations on stator and rotor side respectively [24], [25]. 


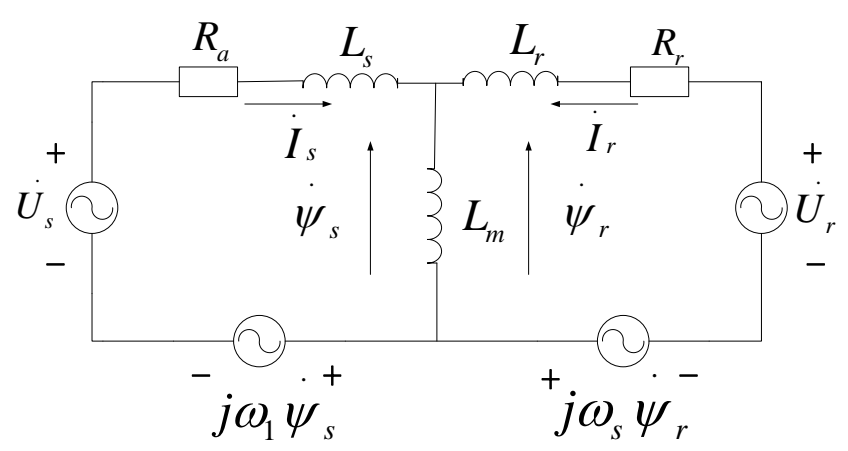

Fig. 2. Equivalent circuit of DFIG.

The generator's electromagnetic torque is related to the stator and rotor currents as follows:

$$
T_{e}=n_{p} L_{m}\left(i_{q s} i_{d r}-i_{d s} i_{q r}\right)
$$

where $\mathrm{n}_{\mathrm{p}}$ is the number of pole pairs number, and $\mathrm{L}_{\mathrm{m}}$ is the mutual inductance between stator and rotor winding $(\mathrm{mH})$. Subscript of the currents indicates whether it is the current of the stator or rotor and whether in the $\mathrm{d}$ or q frame (A).

For a WT operating below rated wind speed and power, a Maximum Power Point Tracking (MPPT) control strategy is realized by controlling electromagnetic torque of the generator. The resultant mechanical torque that is determined by aerodynamic torque and electromagnetic torque is determined that takes the machine's rotational speed to an optimal value in order to maintain an optimal tip-speed-ratio. Stator flux oriented vector control is used for the DFIG to realize MPPT, [26]. The torque control of a DFIG is realized by controlling the currents of its rotor winding. At wind speeds above rated, the turbine maintains constant power output by pitch control.

\section{Powertrain Thermophysics Model}

(1) Power Loss Mechanisms within the WT drivetrain

The energy flow transmitted through the drivetrain and power loss mechanisms within a WT are shown in Fig. 3. The kinetic energy from the wind is converted into electricity with certain efficiency, where the transmission efficiency of the gearbox and the energy conversion efficiency of the generator are the main concerns of this paper. The lost energy is dissipated as heat. Active cooling systems are the main means for dissipating this heat, and include the oil lubrication system of the gearbox and the ventilation system of the generator. Hence, the thermal performance of these systems is essential to maintain acceptable temperatures and operational conditions. Deterioration of the drivetrain components will often be reflected in a reduced efficiency of energy transfer and thus in elevated temperatures. 


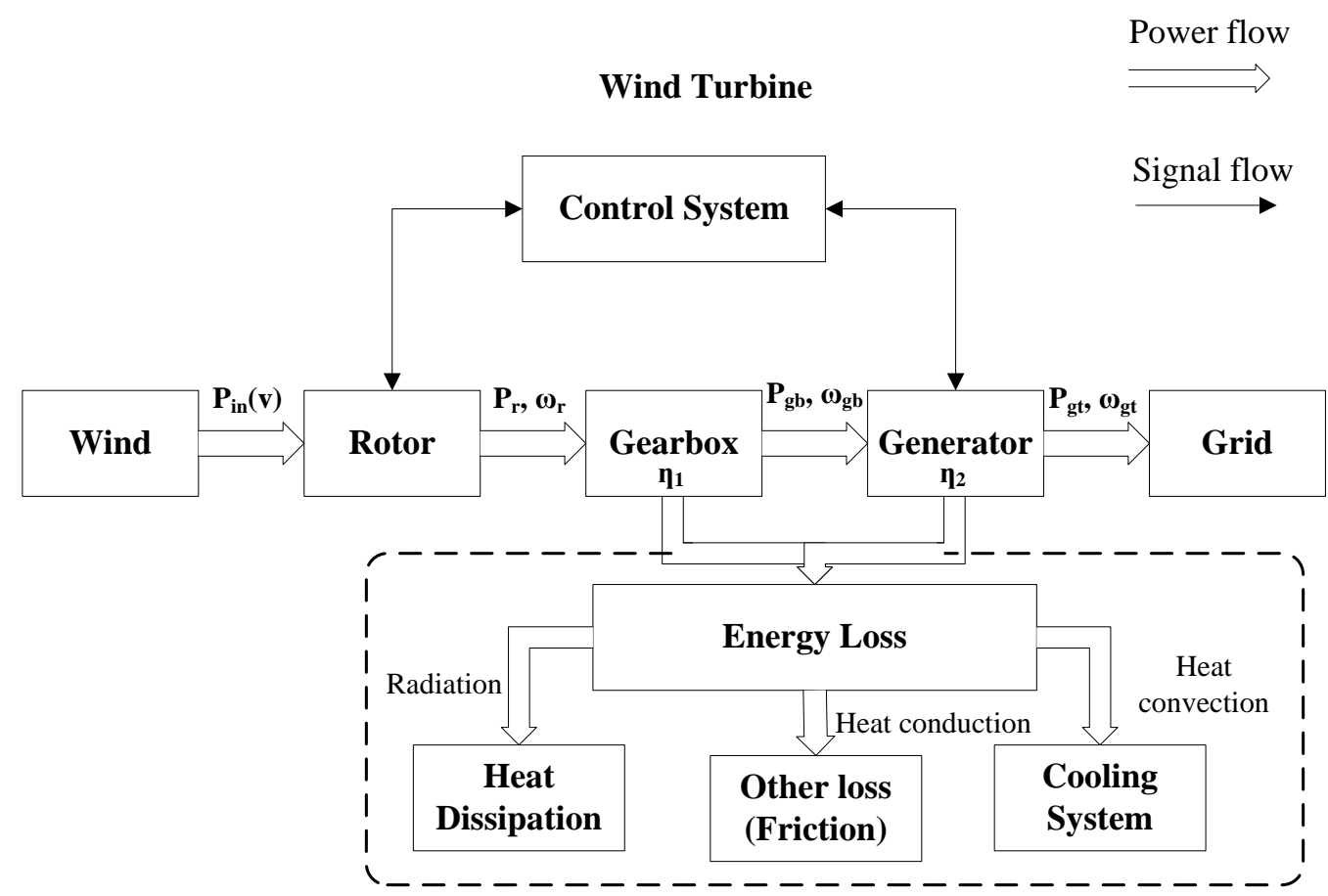

Fig. 3. Energy flow within WT Powertrain and power loss mechanisms.

The losses in a WT system include mechanical losses associated with gearbox friction, and copper (or conduction) losses, iron losses and stray load losses associated with the generator [27]. Mechanical loss is the main loss mechanism within the gearbox. Copper loss is the primary loss of the generator windings while iron loss includes eddy current loss and hysteresis loss. These are the basic losses for a DFIG stator under normal operation. In addition the generator will have bearing and windage losses.

The power losses that have significant influence on gearbox performance include [28] and [29]:

- Load dependent losses - accounting for tooth friction losses due to sliding between gear teeth, and friction between rolling bearing elements.

- No-load dependent losses or churning power losses - viscous friction between all mechanical elements and the fluid where they are immersed.

In the model here, degradation of gearbox transmission efficiency is associated with the overall variation of the losses mentioned above, which reflects the total energy loss associated with the energy transmission. This paper considers that the magnitude of total power loss from a gearbox is determined by its overall transmission efficiency. Thermal equilibrium of the gearbox system is assumed so that power loss inside the gearbox housing is equal to the heat flow dissipated from gearbox.

A WT DFIG is essentially an induction generator. Iron loss is less than copper loss and is not affected by the load; therefore the iron loss is neglected in this study [30].

(2) Gearbox Lubrication System and its Thermophysics 


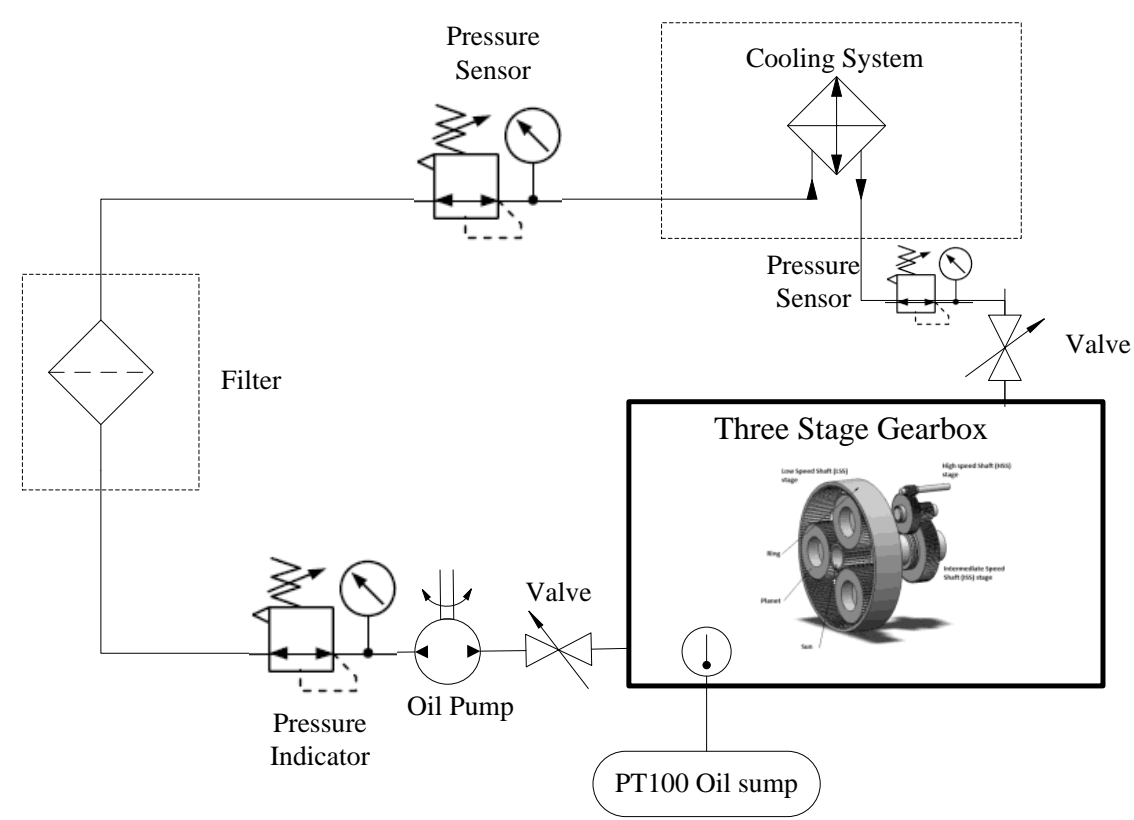

Fig. 4. Schematic of WT gearbox lubrication system.

The primary functions of the gearbox lubrication system is to reduce transmission power losses by decreasing friction between the drive gears and thus to improve gear transmission efficiency, and then to remove this heat, [31]. A schematic of a typical WT gearbox lubrication system is illustrated in Fig. 4. It mainly consists of oil pump unit, heat exchange unit and oil filter unit. The oil pump unit includes motor, pump and filters. Pressure sensors are installed at both ends of the filters to monitor the status of the filters. The parameter for the oil cooling system is the temperature that initiates cooling, which is $60^{\circ} \mathrm{C}$ in this paper. However, for some gearbox system, $-15^{\circ} \mathrm{C}$ is the minimum allowable temperature and above this extra heating is triggered. The ambient temperature for the case studied here is $20^{\circ} \mathrm{C}$ and the gearbox temperature is consistently above $20^{\circ} \mathrm{C}$, so that additional heating does not need to be modelled. Oil filters are used to filter impurities or metal particles within the lubrication oil in order to maintain oil quality and to prevent further wear of the gearbox mechanical components. A temperature sensor is installed in the oil sump to measure lubrication oil temperature.

Due to high conductivity within the gearbox, it can safely be assumed that it has a homogeneous temperature distribution (so that its surface temperature is uniform), and since the data and analysis here is for ten minute time intervals, thermal equilibrium is achieved and the energy flows are constant for each time period. The temperature of gearbox can then be determined by considering the heat generation and the steady state heat transfer affecting the gearbox. Heat from the gearbox is dissipated through three different mechanisms: heat conduction, heat convection and thermal radiation. According to StefanBoltzmann law, the calculated thermal radiation of the gearbox is about $60-100 \mathrm{~W}$ which small enough to 
be neglected. Therefore, in this model, the following heat flows are modelled to calculate the equilibrium temperature of gearbox, [31]:

heat convection and conduction to the external environment from the gearbox, which is represented by $\mathrm{P}_{1}$;

heat exchange by oil supplied via the oil cooling system, represented by $\mathrm{P}_{2}$;

heat lost to the adjacent components by conduction through the coupling shaft, base and all internal components, represented by $\mathrm{P}_{3}$.

If the gearbox input power is $P$, its transmission efficiency is $\mathrm{y}$, the total heat loss $\mathrm{P}_{\text {total }}$ which is the sum of $\mathrm{P}_{1}, \mathrm{P}_{2}, \mathrm{P}_{3}$ can be expressed as follows:

$$
\begin{aligned}
& P(1-\eta)=P_{\text {total }} \\
& P_{1}=\alpha_{G} A\left(T_{G}-T_{a m b}\right) \\
& P_{2}=c \rho Q_{\varepsilon}\left(T_{G}-T_{0}\right) \\
& P_{3}=c M\left(T_{G}-T_{a m b}\right) / t
\end{aligned}
$$

where $\alpha_{G}$ is the overall gearbox casing to ambient heat transfer coefficient, $\mathrm{W} /\left(\mathrm{m}^{2} \cdot \mathrm{K}\right)$. For unhindered still air convection, it is in the range is 15 to $25 \mathrm{~W} /\left(\mathrm{m}^{2} \cdot \mathrm{K}\right)$. A is the surface area of the gearbox casing, $\mathrm{m}^{2}$. Its length is set as $3225 \mathrm{~mm}$, height is $1000 \mathrm{~mm}$, and width is $1400 \mathrm{~mm}$ in this paper, so the heat radiation area is $13.8 \mathrm{~m}^{2}$. In this paper, the nacelle is assumed to be well ventilated so the nacelle air temperature is equal to the ambient temperature. In this way the nacelle itself can be ignored (ie it places no thermal resistance in the heat loss path from the gearbox casing). $\mathrm{T}_{\mathrm{G}}$ is lubrication oil temperature, $\mathrm{K}$. $\mathrm{T}_{\mathrm{amb}}$ represents ambient temperature, $\mathrm{K}$. $\mathrm{c}$ is the specific heat capacity of the cooling medium, $\mathrm{J} /(\mathrm{kg} \bullet \mathrm{K})$, which is generally taken to be 2000. $\rho$ is the density of oil, $\mathrm{kg} / \mathrm{m}^{3}$, which is taken as $900 . \mathrm{Q}_{\varepsilon}$ represents the flow rate of the cooling loop, which is assumed to be constant and estimated to be $1.05 \times 10^{-3} \mathrm{~m}^{3} / \mathrm{s}$. $\mathrm{T}_{0}$ is the temperature of the cooling medium of lubrication and cooling system, $\mathrm{K}$, which is set as $50^{\circ} \mathrm{C}$. $\mathrm{M}$ is the mass, $\mathrm{kg}$, of the gearbox and $\mathrm{t}$ is time, $\mathrm{s} . \mathrm{P}_{1}, \mathrm{P}_{2}$ and $\mathrm{P}_{3}$ are coupled into wind turbine model in order to calculate lubrication oil temperature which essentially affected by ambient temperature (the external environment), cooling system operational situation and wind speed. P1, P2 and P3 are used only to calculate steady state lubrication oil temperature of different wind speeds by assuming that negligible thermal radiation from the surface of gearbox and regarding the nacelle as providing no thermal resistance between the gearbox and the external environment.

(3) DFIG Lumped Parameter Thermal Model 
The thermal analysis of a generator is a complex problem where a great number of thermal-exchange phenomena are involved. In fact, conduction, natural and forced convection and radiation are all present, which are affected by the machine's electrical performance and its specific ventilation system design (natural cooling, fan cooling etc.). A coupled thermal-electromagnetic analysis and lumped circuit parameter model is adopted here.

The copper loss of the stator winding is defined as [32], [33]:

$$
P_{\text {loss }}=3 R_{s} I_{r m s}{ }^{2}
$$

where $R_{s}$ is the stator winding resistance, $I_{r m s}$ is the effective value of the current in each phase. To consider the temperature effects to stator winding resistance, it is calculated as following:

$$
R_{s}=R_{s}^{\prime}(1+\alpha \Delta T)
$$

where $R^{\prime}$ is the initial resistance of stator winding and $R_{S}$ is its final value after temperature variation $\Delta \mathrm{T}$ temperature. $\alpha$ is temperature coefficient of stator winding resistance. As already mentioned, for a high power induction generator, iron losses are less than copper loss which makes copper loss the main heat sources of a generator. In addition, as iron loss is normally not affected by loads it can be neglected when considering the variable speed operation of the turbine. Copper loss is the main sources of stator winding heating; the associated thermal mechanism can be represented by a lumped parameter thermal model as shown in Fig. 5. This is used to predict generator temperature variation due to the way that the variable external wind speed determines power generation, and also to account for other environmental influences.

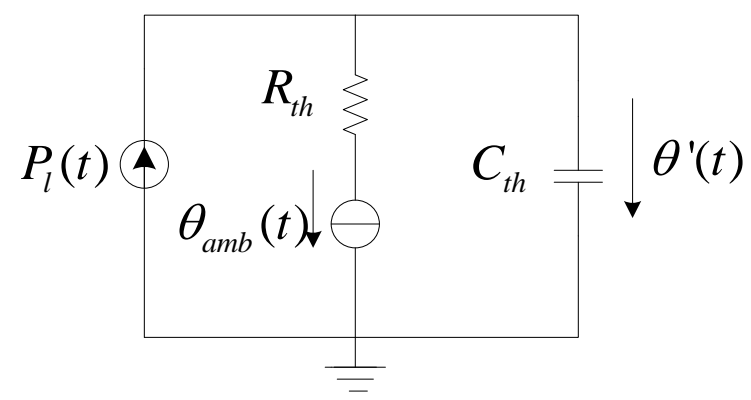

Fig. 5. Simplified lumped parameters thermal model of stator winding.

$\mathrm{P}_{1}(\mathrm{t})$ is the heat source which represents the power loss within the DFIG. $\mathrm{R}_{\mathrm{th}}$ is thermal resistance between the generator windings and the ventilation air (assumed to be at the ambient air temperature $\Theta_{\mathrm{amb}}(\mathrm{t})$ and which allows for variations in environmental conditions in time), and $\mathrm{C}_{\mathrm{th}}$ is the thermal capacity of the stator. The thermal resistance $\mathrm{R}_{\mathrm{th}}$ is the result of summing parallel resistances representing thermal conduction, convection and radiation. 
With the equivalent thermal network model established above, the thermodynamics of the stator winding can be derived from:

$$
C_{t h} d \theta^{\prime}(t) / d t+\theta^{\prime}(t) / R_{t h}=P_{l o s s}(t)
$$

The transfer function can be derived and expressed:

$$
G(s)=\theta(s) / P_{l o s s}(s)=R_{t h} /\left(1+\tau_{t h}\right)
$$

where $\tau_{\mathrm{th}}=\mathrm{R}_{\mathrm{th}} \mathrm{C}_{\mathrm{th}}$ is derived from equation (13) and (14). The simplified thermal model is essentially a low-pass filter with cut-off frequency of $\omega_{\mathrm{c}}=1 / \tau_{\mathrm{th}}$. The value of $\tau_{\mathrm{th}}$ represents how fast the temperature varies with the generator losses. The equations above are used to calculate the steady state temperature under given conditions.

\section{Model Validation and Case Study}

The 10-minute SCADA data used in this study is collected from a $1.5 \mathrm{MW}$ WT with a DFIG. The WT control system acquires real-time signals from sensors installed at specific locations within subassemblies, averages these over ten minutes, and then transmits these 10-minute averages to the wind farm database, including output power, wind speed, rotor rotational speed, main shaft rotational speed, gearbox lubrication system oil temperatures, generator stator winding temperature, ambient temperature [7]. The SCADA data are sensitive to machinery response to internal and external conditions. Based on the above analysis of WT powertrain thermophysics, it is clear that the temperatures of the gearbox oil and the DFIG stator winding reflect drivetrain energy flow and efficiency. Their variations due to wind speed and ambient temperature are studied through simulation and the results compared to SCADA data measurements. The parameters used for the simulation model are listed in TABLE I.

\begin{tabular}{|c|c|c|}
\hline $\begin{array}{c}\text { Sub- } \\
\text { system }\end{array}$ & Parameters & Values \\
\hline \multirow[t]{2}{*}{ WT } & Wind Turbine Rated Power & $1400-1500 \mathrm{~kW}$ \\
\hline & Wind speed, cut-in and rated and cut-out & $3,12,25 \mathrm{~m} / \mathrm{s}$ \\
\hline \multirow[t]{2}{*}{ Rotor } & Wind rotor radius & $31 \mathrm{~m}$ \\
\hline & Wind rotor inertia & $2460106 \mathrm{~kg} \cdot \mathrm{m}^{2}$ \\
\hline Gearbox & Gearbox gear ratio & 78.95 \\
\hline \multirow[t]{7}{*}{ Generator } & Inertia moment & $52 \mathrm{~kg} \mathrm{~m}^{2}$ \\
\hline & $\begin{array}{l}\text { Synchronous speed } \\
\text { (Speed range: } \pm 20 \%-30 \% \text { ) }\end{array}$ & 1500rpm \\
\hline & Pole pair number & 2 \\
\hline & Stator winding resistance & $0.016 \Omega$ \\
\hline & Stator winding leakage reactance & $0.23 \Omega$ \\
\hline & Rotor winding resistance & $0.023 \Omega$ \\
\hline & Rotor winding leakage reactance & $0.18 \Omega$ \\
\hline
\end{tabular}

TABLE I. Parameters used in the simulation model 


\section{(1) Gearbox Case Study}

Gearbox efficiency essentially depends on the number of gear stages and to a lesser extent on the individual stage gear ratios, on the load (determined by the power input to the gearbox) as this affects frictional losses, and the speed as this affects frictional and churning losses. Therefore it is a parameter that varies with load [20]. But it is difficult to obtain the exact information of gearbox efficiency versus load curves. In this paper, the efficiency of gearbox nonlinearly increases with output power, from $66 \%$ at less than $10 \%$ of rated output power to $97.5 \%$ near rated power is assumed, which is similar to the curve presented in [20]. To model the degraded gearbox efficiency, the dotted line in Fig 6 is used which is based on an assumed 1 to 5\% efficiency degradation depending on the output power. This assumption is actually further supported by agreement between this simulation result and results from the SCADA data.

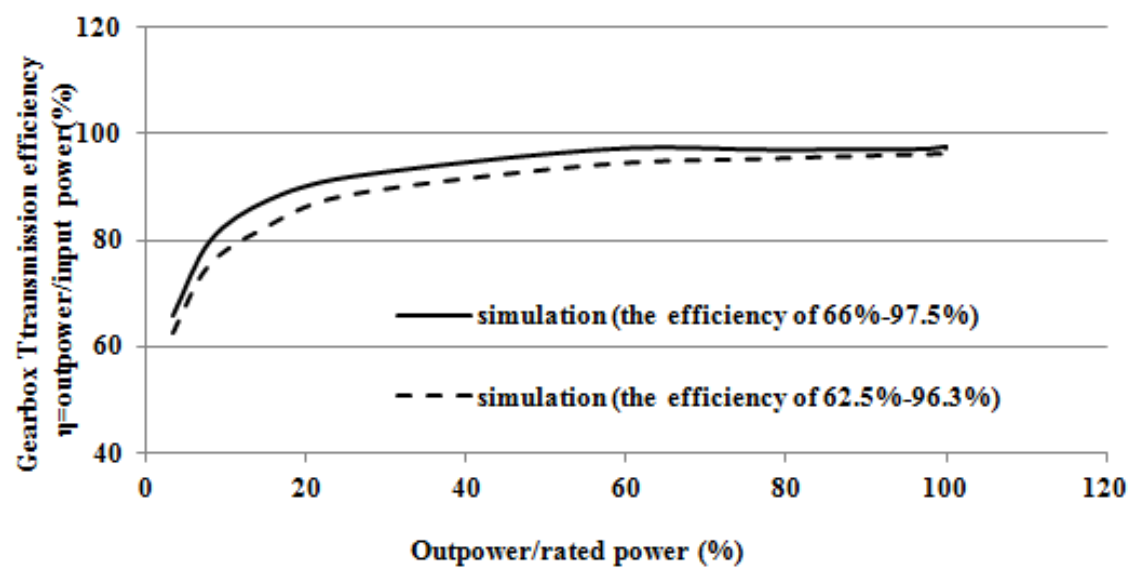

Fig. 6. Degradation of gearbox efficiency (higher efficiency condition in solid line, lower efficiency condition in dotted line).

SCADA data from a wind turbine with a known gearbox fault within a planetary gear stage is used. The data are divided into three different time periods: 9 months, 6 months and 3 months before ultimate gearbox failure. Each dataset contains 3 months of data. The results are compared with the simulation modelling of a suitably degraded gearbox. As show in Fig. 7, the solid and dotted lines are calculated power curves for the original and degraded gearbox respectively, and the scattered points are the binned averaged power output of WT taken from the SCADA data for the three different time periods. 


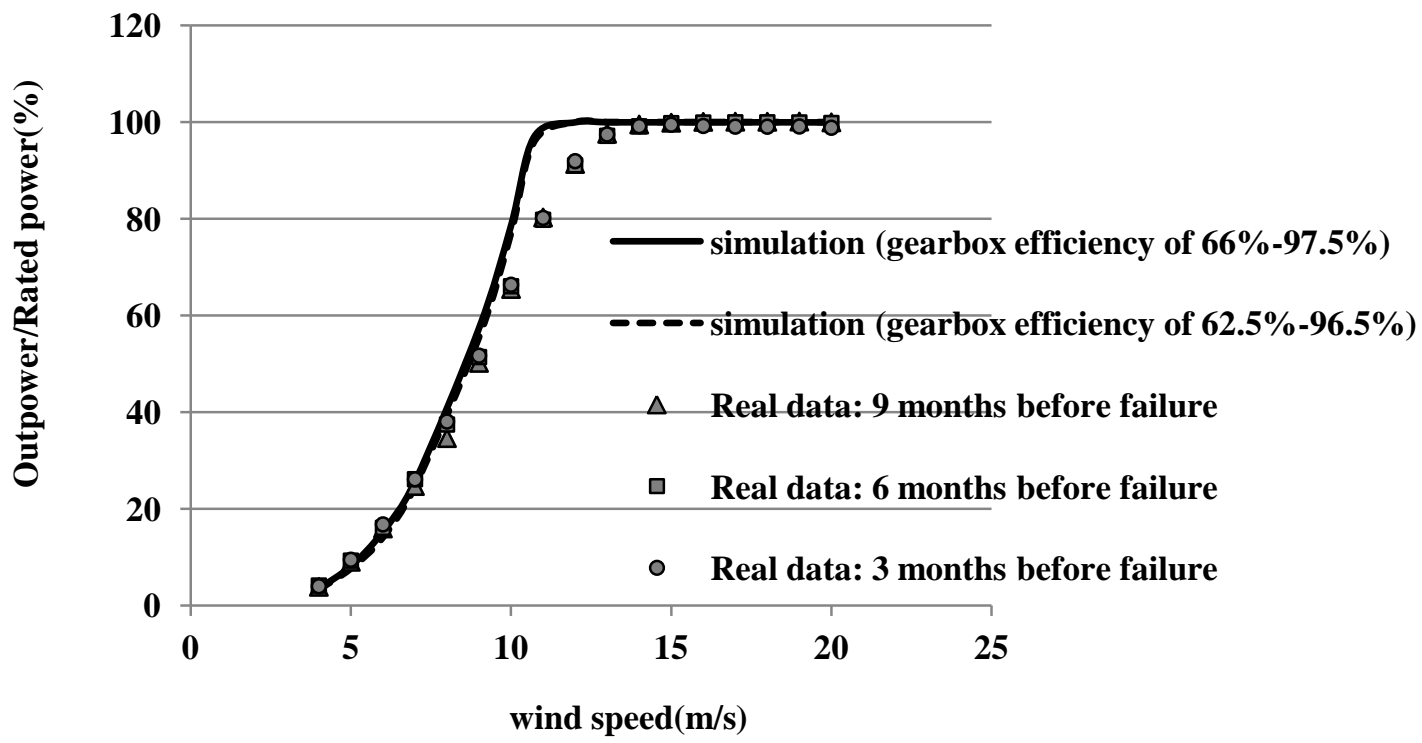

Fig. 7. Power curves achieved by simulation and SCADA data analysis.

The figure shows good agreement of low and high wind speed trends in the power curve for both the simulation results and the SCADA data. Due to the differences in control strategy and control parameters, there are slight deviations in power output around the rated wind speed range. Although the degradation of gearbox efficiency will result in slight decrease of output power, the differences of two conditions is not obvious in the power curve. In the figure, the simulated power curves for the two different gearbox conditions nearly overlap, while the clustered SCADA data for the three time periods are not much different. Therefore, monitoring the WT power curve is not expected to be an effective approach for the detection of gearbox efficiency degradation.

Alternatively equations (7) to (10) can be used to calculate the equilibrium gearbox lubrication oil temperature for a given wind speed from which $\mathrm{P}$ is calculated from the power curve for use in equation (7). The resulting variation of gearbox oil temperature with wind speed is shown in Fig. 8. It shows the simulation results and binned SCADA data. Oil temperature rise is defined as absolute oil temperature minus ambient temperature to exclude environmental impact. 


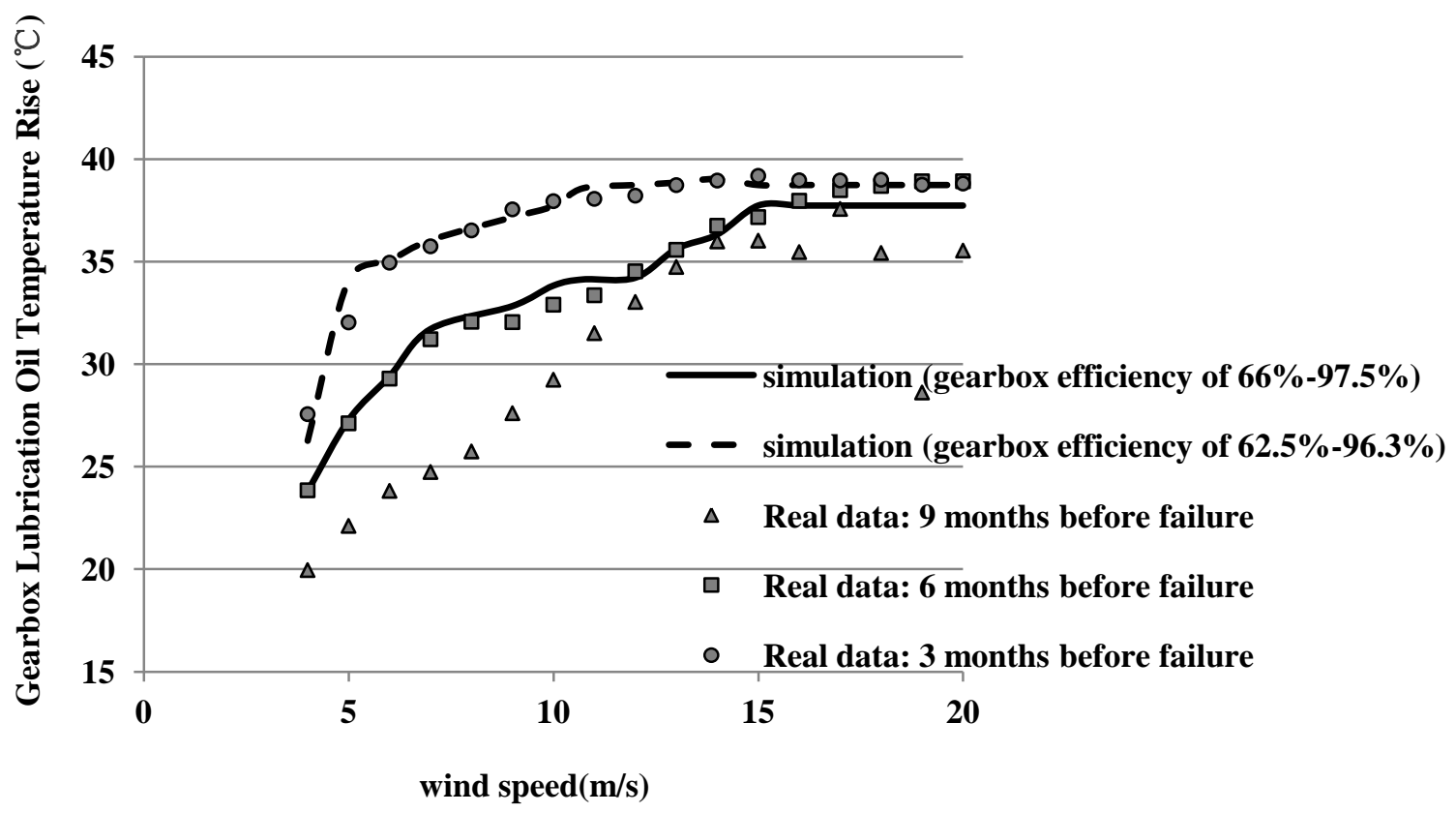

Fig. 8. Gearbox oil temperature rise vs wind speed for decreased gearbox efficiency.

Fig. 8 shows that a slight degradation of gearbox efficiency leads to an obvious temperature rise. This can be explained from the thermophysics in Section 3 since lubrication oil temperature will rise above that for normal operating conditions due to extra losses reflected in the values of $\mathrm{P}_{1}, \mathrm{P}_{2}, \mathrm{P}_{3}$. Compared to the power curve in Fig. 7, the signature of gearbox efficiency degradation is much clearer in Fig. 8. The simulation results match quite well with the SCADA data in 6-month and 3-month period before failure, which confirms the thermal model and loss mechanism of gearbox. Due to insufficient data for the period 9 months before failure, low quality of the data at this period makes its trend not agree well with simulation result. But the observation confirms that during this period the gearbox may have an even higher transmission efficiency which causes lower temperature rise of gearbox oil. A minor decrease in efficiency at wind speeds between 7 and $9 \mathrm{~m} / \mathrm{s}$ is observed in SCADA data from 6-months before failure. This is mainly due to the triggering of cooling system that affects $P_{2}$ in the equation (9) when oil temperature rises above $60{ }^{\circ} \mathrm{C}$. The initial start of the cooling system results in a reduction of oil temperature rise. The few data points in 9-month period dropping below the trend at a wind speed of around $19 \mathrm{~m} / \mathrm{s}$ are mainly attributed to insufficient data samples.

Although Fig. 8 shows the analytical result for oil temperature rise in different time periods, it does not describe the relationship between ambient conditions and the gearbox oil temperature. In Fig.9, the oil temperature rise at a wind speed $10 \mathrm{~m} / \mathrm{s}$ is plotted against ambient temperature. It is clear that the oil temperature rise decreases linearly with the increase of ambient temperature that varies from $10^{\circ} \mathrm{C}$ to $40^{\circ} \mathrm{C}$. 
Even if the gearbox approaches failure, the linear relationship is maintained except it shifts upwards vertically, indicating a 2 to $5^{\circ} \mathrm{C}$ temperature increases of the lubrication oil. From Fig 9, it is quite obvious that maximum gearbox oil temperature is limited by the cooling system. Once oil temperature rises over this limit, cooling system is initiated to remove any further losses in order to maintain temperature.

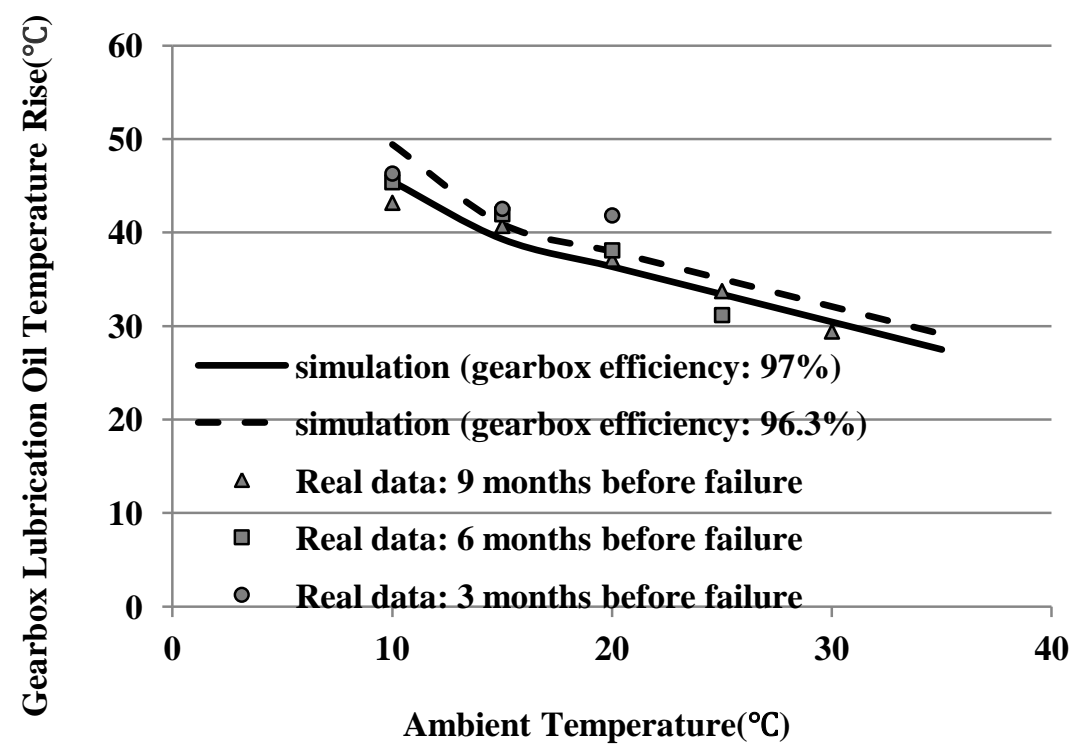

Fig. 9. Relationship of ambient temperature to gearbox lubrication oil temperature rise at wind speed $10 \mathrm{~m} / \mathrm{s}$.

(2) Generator Case Study

With equations (11) to (14), the generator stator winding temperature is calculated and plotted against power output as shown in Fig. 10. SCADA data before and after the DFIG ventilation failure is divided into two groups (circular points and square points, respectively). For the model to simulate the generator stator winding temperature without ventilation failure, initial parameters of $\mathrm{R}_{\mathrm{th}}$ and $\mathrm{C}_{\mathrm{th}}$ are set as $0.0101 \mathrm{~K} / \mathrm{W}$ and $19200 \mathrm{Ws} / \mathrm{K}$, respectively. In equation (13), the stator winding resistance is set to $0.016 \Omega$ and its temperature coefficient is chosen as $0.0039 \Omega / \mathrm{K}$. By fitting the parameters of thermal resistance $\mathrm{R}_{\mathrm{th}}$ and thermal capacity $\mathrm{C}_{\text {th }}$ in the DFIG thermal model with ventilation failure, simulation shows $\mathrm{R}_{\text {th }}$ increasing to $0.0174 \mathrm{~K} / \mathrm{W}$ with $\mathrm{C}_{\text {th }}$ maintaining the same value at $19200 \mathrm{Ws} / \mathrm{K}$. The variations in the model parameters $R_{\text {th }}$ suggest the significant change of heat transfer mechanism within the system. Due to the increase of the internal temperature of the DFIG, the stator winding resistance will increase with the temperature coefficient of $0.0039 \Omega / \mathrm{K}$ for copper. This leads to a further increase in power loss. The increase of power loss and the variation of thermal resistance will lead to the increase of winding temperature rise. For an air-cooled generator, the failure of the ventilation system essentially leads to heat transfer inside the generator to change from forced convection to natural convection. The heat is more difficult to dissipate under this situation, which leads to the increase of convection resistance coefficient. 
And then the temperature rise is more significant in the generator, which is seen as an increase of standard deviation of the generator temperature signals. Root cause analysis found the ventilation system fails due to a fan motor failure.

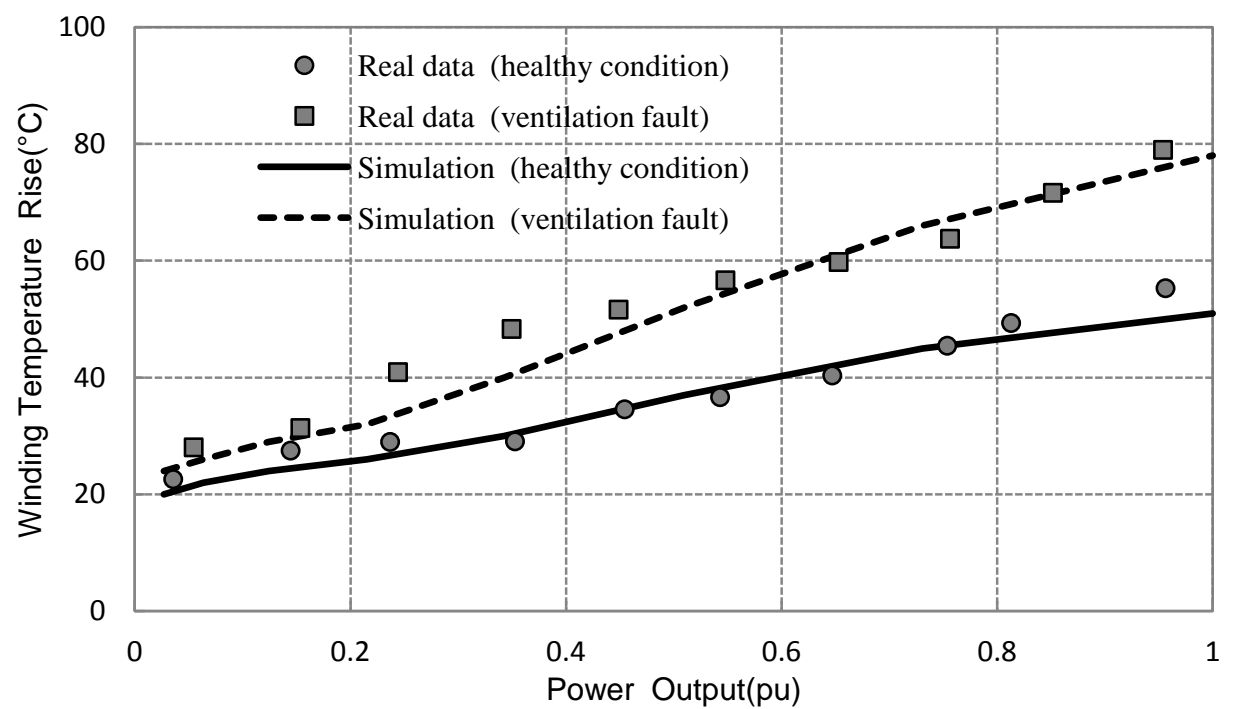

Fig. 10. Stator winding temperature vs normalized WT power output before and after ventilation failure.

To simulate voltage unbalance on the stator winding and its subsequent effects on stator temperature voltage unbalance, also known as the phase voltage unbalance rate (PVUR), according to the IEEE is defined as:

$$
\text { PVUR }=\frac{\text { Max.Phase.Voltage }- \text { Avg.phase..Voltage }}{\text { Avg.PhaseVoltage }} \times 100 \%
$$

The average voltage in equation 15 refers to temporal average. 5\% overvoltage is set for three phases in the simulation in order to compare to the real data. SCADA data with 5\% overvoltage for three phases are filtered and plotted in Fig. 11. For the case of asymmetric voltage for the three phases please refer to [34]. 


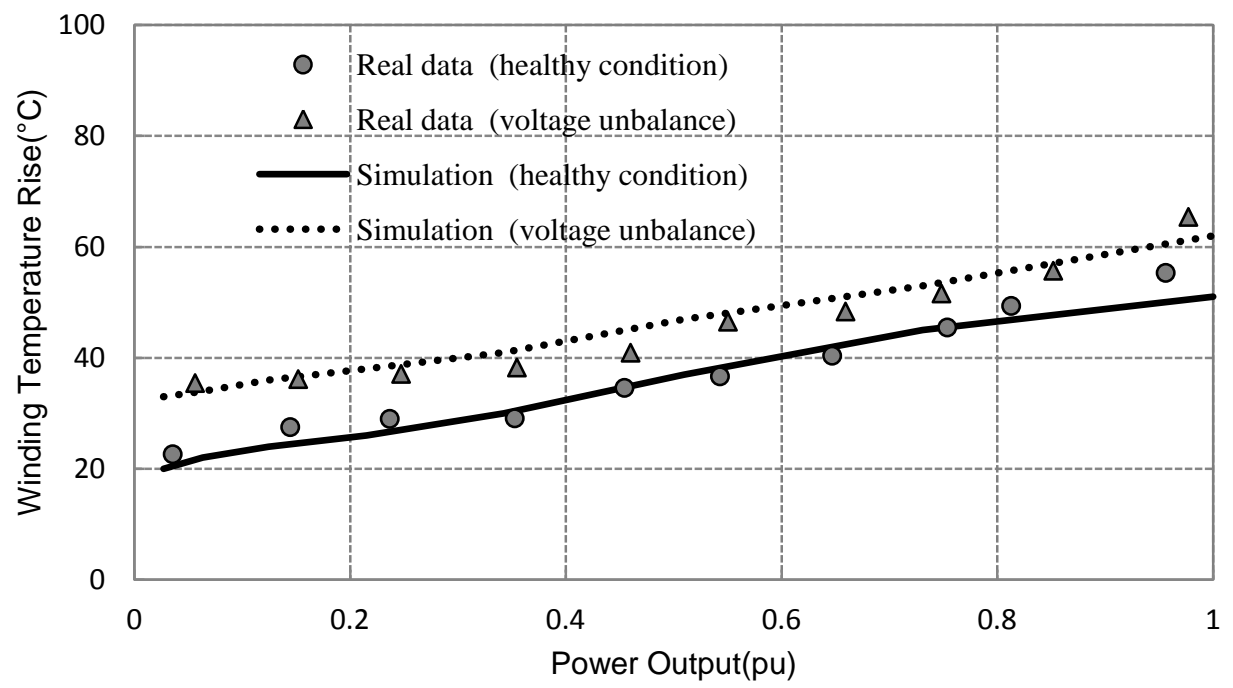

Fig. 11. Stator winding temperature vs normalized WT power output for voltage unbalance.

There are several causes leading to voltage unbalance such as incomplete transposition of transmission lines, unbalanced loads, open delta transformer connections, blown fuses on three-phase capacitor banks. Voltage unbalance will have a direct impact on generator output current, which further affects the losses in the generator. In this case, both current and resistance of the stator winding increased while the thermal resistance and capacity is the same as for the healthy situation. The result shows that $5 \%$ overvoltage on the DFIG leads to a $6-12 \mathrm{~K}$ ( or ${ }^{\circ} \mathrm{C}$ ) temperature increase in the generator stator winding. The magnitudes of temperature increases are nearly in proportion for different power generation rates, as indicated by the same gradient as shown in the plot.

Different features of the above two failure modes are clearly observed. When the ventilation system is faulty, the gradient of the curve relating the stator winding temperature to output power increases. However, when the stator supplied voltage has a 5\% over-voltage, the gradient of stator winding temperature against power output is the same as for the healthy condition. However, the intercept of the curve increases sharply in the later case. These phenomena confirm the different thermal mechanisms are at work within generator. The voltage unbalance will have a direct impact on the generator power loss magnitude in the DFIG, while the ventilation failure leads to a variation of the thermal parameters.

\section{Discussion \& Conclusion}

Table II summarizes the failure modes studied in this paper and the diagnostic rules applicable using SCADA data. Gearbox gear wear, teeth corrosion or pitting attributed to fatigue, and lubrication system failure or oil quality degradation can be monitored by oil temperature rise. Generator ventilation failure which may be due to fan motor failure of an air-cooled generator can be monitored through winding 
temperature variations. Unbalanced loads, open delta transformer connections or blown fuses on three phase capacitor banks that may cause voltage unbalance on the generator winding can be distinguished by different winding temperature patterns. The diagnostic rules summarized provide a cost effective way to monitor the WT powertrain, providing condition monitoring for failure modes that may not be possible using vibration analysis. The results are also useful for optimizing WT powertrain lubrication and cooling systems by understanding the thermal mechanism within the drive train of a WT and its temperature features under certain failure modes.

TABLE II. Summary of diagnostic rules

\begin{tabular}{|c|c|}
\hline Failure Modes & Diagnostic Rules \\
\hline Gearbox: gear teeth broken failure & $\begin{array}{l}\text { (1) Power transmission efficiency degradation } \\
\text { (2) Lubrication oil temperature rise (against wind speed or } \\
\text { output power) }\end{array}$ \\
\hline Generator: ventilation system failure & $\begin{array}{l}\text { (1) Stator winding temperature rise (against wind speed or } \\
\text { output power) and curve gradient increases. } \\
\text { (2)Winding temperature magnitude become dispersed }\end{array}$ \\
\hline $\begin{array}{l}\text { Generator: winding voltage } \\
\text { unbalances }\end{array}$ & $\begin{array}{l}\text { (1) The curve of winding temperature against output power } \\
\text { shift vertically (with the same gradient). }\end{array}$ \\
\hline
\end{tabular}

A thermal model of variable-speed 1.5 MW WT configured with a gearbox and DFIG is presented in this paper. The comparison between simulation results and SCADA data validates the model and the proposed thermophysics of the WT gearbox and generator. Heat transfer mechanisms for the gearbox lubrication system and generator ventilation system are important for developing WT powertrain fault diagnostic algorithms using SCADA data. The model based simulation and the corresponding SCADA data analysis shows:

1. The gearbox oil temperature rise is due to the degradation of gearbox efficiency while its magnitude is jointly determined by the power transmitted and the ambient temperature.

2. The nonlinear relationship between gearbox oil temperature rise and wind speed/ output power is due to the efficiency nonlinearity and the efficiency degradation rate for the gearbox experiencing failure, meanwhile the oil temperature rise exhibits a linear relationship with ambient temperature.

3. Ventilation system failure of the generator essentially causes an increase of winding resistance, thermal resistance of LPN model, which subsequently results in an increasing gradient of the relationship between stator winding temperature and output power. 
4. The DFIG stator winding under voltage unbalance experiences an increase in power loss which subsequently leads to an increase in winding temperature. The temperature increase due to voltage unbalance is not affected by the variable output power.

According to the failure features obtained, a fault detection algorithm can be integrated into the SCADA system to facilitate accurate failure detection which can deliver low cost condition monitoring and fault diagnosis.

\section{Acknowledgments}

This research work is funded by: The Natural Science Foundation of Jiangsu Province (BK20131350); Start-up Scientific Research Project of NUST, Jiangsu Top Six Talent Summit Fund (ZBZZ-045); Returned Overseas Students Preferred Funding; and Fundamental Research Funds for the Central Universities (No. 30915011324). National Natural Science Foundation of China (Grant No. $51505225)$.

\section{References}

[1] Z. Hameed, Y.S. Hong, Y.M. Cho, S.H. Ahnb, C.K. Song, :'Condition Monitoring and Fault Detection of Wind Turbines and Related Algorithms: A Review', Renew. Sustain. Energ. Rev. 2009, 13, pp. 1-39.

[2] Y. Amirat, M.E.H. Benbouzid, E. Al-Ahmar, B. Bensaker, S. Turri,: 'A brief status on condition monitoring and fault diagnosis in wind energy conversion systems', Renew. Sustain. Energ. Rev. 2009, 13, pp.2629-2636.

[3] Edwin Wiggelinkhuizen, Theo Verbruggen, Henk Braam, Luc Rademakers, Jianping Xiang, Simon Watson,: 'Assessment of Condition Monitoring Techniques for Offshore Wind Farms', J. Sol. Energ. Eng. 2008, 130, 0310041- 9 .

[4] Wenxian Yang, Peter J. Tavner, Christopher J. Crabtree, Y. Feng, Y. Qiu,: 'Wind turbine condition monitoring: technical and commercial challenges', Wind Energ. 2014, 17, pp.673-693.

[5] Fausto Pedro García Márquez, Andrew Mark Tobias, Jesús María Pinar Pérez, Mayorkinos Papaelias,: 'Condition monitoring of wind turbines: Techniques and methods', Renew. Energ. 2012, 46, pp. 169-178.

[6] Yanhui Feng, Yingning Qiu, Christopher J Crabtree, Hui Long, Peter J Tavner,: 'Use of SCADA and CMS signals for failure detection and diagnosis of a wind turbine gearbox', EWEA 2011, Brusels.

[7] Yanhui Feng, Yingning Qiu, Christopher J. Crabtree, Hui Long, Peter J. Tavner,: 'Monitoring wind turbine gearboxes', Wind Energ., 2012, 16, pp. 728.

[8] A.Zaher, S.D.J.McArthur, D.G.Infield,: 'Online Wind Turbine Fault Detection Through Automated SCADA Data Analysis', Wind Energ. 2009, 12, pp. 574-593.

[9] Wenxian Yang, Richard Court, Jiesheng Jiang,: 'Wind turbine condition monitoring by the approach of SCADA data Analysis', Renew. Energ. 2013, 53, pp. 365-376. 
[10] Meik Schlechtingen, Ilmar Ferreira Santos, Sofiane Achiche,: 'Wind turbine condition monitoring based on SCADA data using normal behaviour models. Part 1: System description', Appl. Soft. Computing, 2013, 13, pp. 259-270.

[11] Meik Schlechtingen, Ilmar Ferreira Santos,: 'Wind turbine condition monitoring based on SCADA data using normal behavior models. Part 2: Application examples', Appl. Soft. Computing, 2014,14, pp.447-460.

[12] Peng Guo and David Infield, : 'Wind Turbine Tower Vibration Modeling and Monitoring by the Nonlinear State Estimation Technique (NSET) ', Energies, 2012, 5, 5279-5293.

[13] Khaled B. Abdusamad, David Wenzhong Gao, Eduard Muljadi, : 'A Condition Monitoring System for Wind Turbine Generator Temperature by Applying Multiple Linear Regression Model', North American Power Symposium (NAPS), 2013, 22-24 Sept. 2013, pp. 1-8.

[14] Yingning Qiu, Yanhui Feng, Peter Tavner, Paul Richardson, Gabor Erdos and Bindi Chen,: 'Wind turbine SCADA alarm analysis for improving reliability', Wind Energ. 2012, 15(8), pp. 951-966.

[15] Michael Wilkinson, Brian Darnell, Thomas van Delft, Keir Harman,: 'Comparison of methods for wind turbine condition monitoring with SCADA data', IET Renew. Power Gener, 2014, 8(4), pp. 390-397.

[16] Andrew Kusiak, Wenyan Li,: 'The prediction and diagnosis of wind turbine faults', Renew. Energ. , 2011, 36, pp. 16-23.

[17] Amir Rasekhi Nejad, Peter Fogh Odgaard, Zhen Gao, Torgeir Moan,: 'A prognostic method for fault detection in wind turbine powertrain', Engineering Failure Analysis, 2014, 42, pp.324-336.

[18] Christopher S. Gray, Simon J. Watson,: 'Physics of failure approach to wind turbine condition based maintenance', Wind Energ. 2010, 13, pp.395-405.

[19] Qiu Yingning, Sun Juan; Feng Yanhui,: 'Wind Turbine Fault Simulation', 2nd IET Renewable Power Generation Conference, 2013, p 3.C13 (4 pp.).

[20] Erich Hau,: 'Wind Turbine: Fundametals, Technologies, Application, Economics', Springer, 2nd ed., 2008.

[21] J. G. Slootweg, S. W. H. de Haan, H. Polinder, W. L. Kling,: 'General model for representing variable speed wind turbines in power system dynamics simulation', IEEE Trans. on Power Systems, 2003, 18(1), pp.144-151.

[22] P.M. Anderon, A. Bose,: 'Stability simulation of wind turbine systems, IEEE Trans', Power App. Syst., 1983, 102, pp.3791-3795.

[23] Ezzeldin S.Abdin, Wilson Xu,: 'Control Design and Dynamic Performance Analysis of a Wind TurbimeInduction Generator Unit', IEEE Trans. Trans. Energ. Convers., 2000, 15(1), pp. 91-96.

[24] Xu Yin, Chen Ying, Mei Shengwei,: 'Wind turbine transient simulation model', Power Systems, 2011, 35 (9), pp. 100-107.

[25] lulian Munteanu, et al.: 'Optimal Control of Wind Energy Systems: Towards a global approach', Springer London Ltd., 1st ed., Softcover of orig. ed. 2008.

[26] Lie Xu, Yi Wang,: 'Dynamic Modeling and Control of DFIG-Based Wind Turbines Under Unbalanced Network Conditions', IEEE Trans. on Power Systems, 2007, 22, pp. 314-323. 
[27] Inoue A, Takahashi R, Murata T, et al.: 'A calculation method of the total efficiency of wind generators', Electrical Engineering in Japan, 2006, 157(3), pp.52-62.

[28] Changenet C, Velex P,: 'A model for the prediction of churning losses in geared transmissions - preliminary results', Journal of Mechanical Design, 2007, 129(1), pp.128-133.

[29] Höhn B-R, Michaelis K.: 'Influence of oil temperature on gear failure', Tribology International, 2004, 37, pp.103-109.

[30] Rion Takahashi, Hajime Ichita, Junji Tamura.: 'Efficiency Calculation of Wind Turbine Generation System with Doubly-Fed Induction Generator', XIX International Conference on Electrical Machines- ICEM 2010, Rome.

[31] Niemann G. ,Winter H.: 'Maschinenelemente', Springer, 2003.

[32] Demetriades G D, De La Parra H Z, Andersson E, et al.: 'A real-time thermal model of a permanent-magnetic synchronous motor', IEEE Trans. on Power Electronics, 2010, 25(2), pp.463-474.

[33] H. Oraee, A. E. Emanuel,: 'Induction motor useful and power quality', IEEE Power Eng. Rev., 2000, Jan, pp. $47-48$.

[34] Yingning Qiu, Wenxiu Zhang, Mengnan Cao, Yanhui Feng and David Infield. : 'An electro-thermal analysis of a variable-speed doubly-fed induction generator in a wind turbine', Energies, Vol. 8, 2015, pp.3386-402. 